\title{
Research and Design the Thrust Fluctuation of Slotted-Tubular Permanent Magnet Linear Motor: an application on low frequency plastic forming equipment
}

\section{Jingzhou Gao}

Xi'an Jiaotong University School of Mechanical Engineering https://orcid.org/0000-0003-4226-5149

Jingxiang $L i$

Xi'an Jiaotong University

Shengdun Zhao ( $\nabla$ sdzhao@xjtu.edu.cn )

Xi'an Jiaotong University https://orcid.org/0000-0002-9316-915X

Wei Du

Xi'an Jiaotong University

Fei Jiang

Xi'an Jiaotong University

\section{Zheng Zhenhao}

Xi'an Jiaotong University

\section{Xinchu Wu}

Xi'an Jiaotong University

Original Article

Keywords: Low frequency vibration plastic forming equipment, slotted - TPMLM, End force, Cogging force, Electromagnetic thrust force

Posted Date: August 10th, 2021

DOI: https://doi.org/10.21203/rs.3.rs-760628/v1

License: (c) (i) This work is licensed under a Creative Commons Attribution 4.0 International License. Read Full License 


\title{
Research and Design the Thrust Fluctuation of Slotted-Tubular Permanent Magnet Linear Motor: an application on low frequency plastic forming equipment
}

\author{
Jingzhou Gao, Jingxiang Li, Shengdun Zhao*, Wei Du, Fei Jiang, Zhenhao Zheng and Xinchu Wu \\ School of Mechanical Engineering, Xian Jiaotong University, Xi’an, China, 710049
}

Corresponding author: Shengdun Zhao

Email: sdzhao@mail.xjtu.edu.cn

Abstract - In this paper, a novel type of low frequency vibration plastic forming equipment is proposed, in which the slotted tubular permanent magnet synchronous liner motor (slotted - TPMLM) is the core component and plays the roles of power source and vibration source. So, this paper focuses on the research about the design of the slotted - TPMLM. The suppression and optimization of motor thrust fluctuation has always been a hot research issue. But that is not the purpose of this article. Here, the effect of the length of stator core on end force and the influence of the number of poles and slots on the cogging force are discussed in detail. The purpose is to design the thrust fluctuation of slotted - TPMLM reasonably so that the thrust fluctuation can be used in the low frequency plastic forming. The slotted - TPMLM is designed, manufactured, and tested. The experimental results show that the motor can output thrust with periodic fluctuation (low frequency, about $4.8 \mathrm{~Hz}$ ), and the thrust fluctuation accounts for about $16.5 \%$ of the average thrust, which meets the metal low frequency vibration plastic forming requirements. Consequently, the low frequency vibration plastic forming equipment can be realized, which contributes to the field of the plastic forming.

Key words - Low frequency vibration plastic forming equipment, slotted - TPMLM, End force, Cogging force, Electromagnetic thrust force.

\section{INTRODUCTION}

In the material plastic forming, if the processed material or tool is subjected to a certain vibration force, the processing technology and the product quality can be improved on specific occasions, this method is called vibration plastic forming ${ }^{[1,2]}$. The vibration plastic forming can expand the application range of plastic forming, save materials, save energy, and also can form materials with high strength, high hardness, and complex shapes ${ }^{[2,3]}$.

In the vibration plastic forming, ultrasonic vibration is the most widely used, and its effect has been confirmed by many researchers ${ }^{[3]}$. Besides, applying low frequency vibration force (For instance, Q235 and 45, under the test of 0-3 kN vibration force, about $15 \%$ - 45\% of forming force of the materials, frequency less than $300 \mathrm{~Hz}$, the yield strength and ultimate strength of the materials will be significantly reduced ${ }^{[4,5]}$ ) during the plastic forming will also be able to effectively reduce the forming resistance, improve the product quality and mechanical properties, and increase the tensile strength during the plastic forming process, which is called low frequency vibration plastic forming. Furthermore, the low frequency vibration can be applied to the metal extrusion, stretching upsetting, rolling and other plastic processes ${ }^{[2,3]}$.

As a very effective novel concept and technology, low frequency vibration plastic forming has broad market prospects. Therefore, actively developing the low frequency vibration forming equipment will promote the wide application of this technology. Thus, the low frequency vibration plastic forming equipment is the research and application background of this article.

For the equipment, there are two main parts: one is the power source that can complete the normal movement (to ensure the operation of the slider); the other is the vibration source that contains the low frequency vibration force.

Generally, a rotating electric machine is used as the power source ${ }^{[6,7]}$, as shown in Fig.1. Thus, a rotary - linear motion conversion mechanism must be used, which causes the transmission chain to be too long and causes the overall structure of the machine tool bloated.

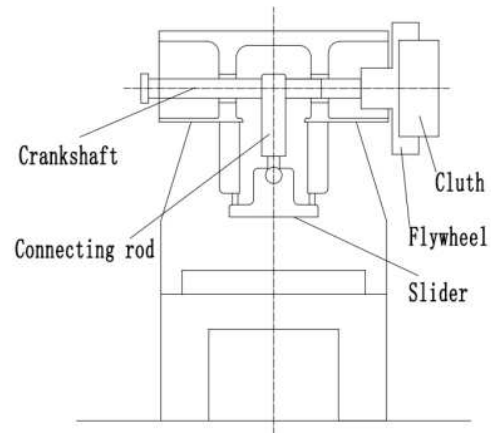

Fig.1 The conventional forming equipment driven by a rotating electric machine. 
In recent years, the rapid development of linear motor has made it possible to use linear motors as power source to achieve direct drive, which has changed the previous drive and transmission form, greatly simplified the transmission chain of the machine tool, reduced maintenance, and saved energy. K. Osakada ${ }^{[7]}$ reviews that forming equipment driven by a linear motor is a future development direction. Halicioglu. ${ }^{[8]}$ and b-a.Behrens ${ }^{[9]}$ summarize the development and application of direct-drive machinery in the field of material forming, and proposed that direct-drive machinery has the characteristics of simple structure, strong controllability and high metal quality.

For those reasons, a linear motor can be used as the power source without a motion conversion mechanism, which can optimize the transmission structure and improve the performance. Therefore, it is feasible and necessary to develop a low frequency vibration forming equipment driven by a linear motor as the power source.

For this equipment, the linear motor must have sufficient thrust to ensure the forming force of material because of the zero transmission structure (short transmission chain) ${ }^{[10,11]}$. In the type of linear motor, the linear induction motor has low operating efficiency and low output thrust; the switch reluctance linear motor has the advantages of strong robustness; the thrust of the permanent magnet synchronous motor is large enough ${ }^{[12,13]}$. Therefore, a permanent magnet synchronous linear motor is selected as the power source to obtain enough forming force.In the permanent magnet synchronous linear motor, slotted tubular permanent magnet synchronous linear motor (Slotted-TPMLM) has been more special attention because of its excellent output characteristic (large enough thrust) and structural characteristic (the tubular structure allows the normal suction to be balanced) ${ }^{[14]}$, as shown in Fig.2. Therefore, a slotted - TPMLM is adopted as the power source of the equipment, as shown in Fig.3. Compared with the equipment in Fig.1, the drive and transmission structure of the equipment in Fig. 3 is greatly simplified.

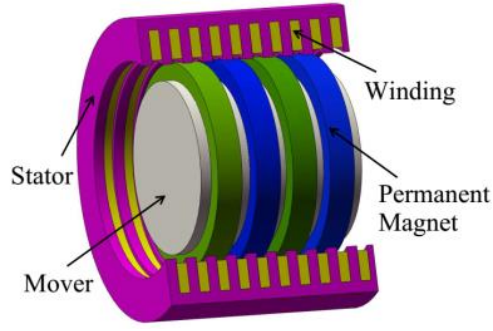

(a) 3D diagram of slotted-TPMLM

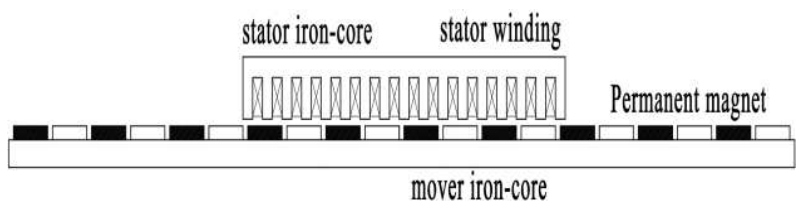

(b) diagram of slotted-TPMLM

Fig.2 The slotted - tubular permanent magnet synchronous linear motor (Slotted - TPMLM)
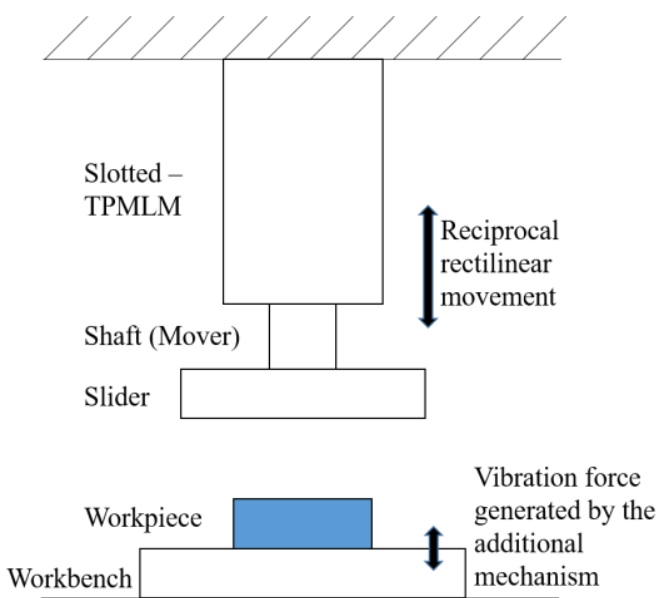

Fig. 3 The slotted - TPMLM as the power source in the low frequency vibration forming equipment.

Although the slotted - TPMLM, which is very suitable for the application of the equipment, has the advantage of large enough thrust, its thrust fluctuation is correspondingly large. The thrust fluctuation of the slotted -TPMLM is mainly affected by the composition of end force, cogging force and electromagnetic thrust ${ }^{[15]}$. Most importantly, the thrust fluctuation cannot be completely eliminated. The end force and the cogging force are only related to the physical structure of the motor ${ }^{[16]}$; the electromagnetic thrust force is related to the physical structure and the excitation current, and is greatly affected by the excitation 
current ${ }^{[17]}$.

According to the relevant research on the thrust fluctuation of the slotted-TPMLM, it can be found that the optimization or suppression of thrust fluctuation of the linear motor has always been a hot topic. Many scholars and researches put forward corresponding optimization and improvement measures according to the factors and characteristics of the thrust fluctuation.

For example, Z.Q Zhu ${ }^{[18,19,20]}$ conducted fourier analysis and energy method on slotted and slot-less TPMLM to obtain the equations about the end force and cogging force, and proposed methods to reduce thrust fluctuation. B.Q. Kou, X.Z Huang and L.Y Li ${ }^{[21-26]}$ optimized the slotted and slot-less TPMLM to improve the thrust density and reduce the thrust fluctuation by optimizing the length, magnetization direction, slot size and other relevant parameters. P.F Hou ${ }^{[27]}$ studied the effect of different slot sizes on the tooth force. N. Bianchi, $\mathrm{S}{ }^{[28]}$ put forward the design criterion of linear motor. J.B Wang ${ }^{[29]}$ optimized the conventional axial magnetized PM motor, studied its thrust density and back electromotive force, and then put forward the design optimization criterion and topology structure. M. Ashabani ${ }^{[30]}$ optimized TPMLM through a multi-objective design of four variables (magnet width, number of slots per pole-piece, slot width, slot depth). K.L. Pan ${ }^{[31]}$ established an analytical model of magnetic resistance generated by the side-effect and put forward the principle and method of optimizing the primary length to reduce the magnetic resistance. J. H. Zhao ${ }^{[32]}$ analyzed the influence of different parameters on thrust density. AW van Zyl ${ }^{[33]}$ optimized the length of the permanent magnet. Q. Wang ${ }^{[34]}$ used virtue work method to study the cogging force, and carried out multi-objective optimization. In addition to the above mentioned, most scholars still studied the thrust fluctuation characteristics of TPMLM and proposed optimization direction.

From the above studies, it is found that the existing research and processing methods all strive to minimize the thrust fluctuation by changing the structure ontology parameters. The most significant effect is to reduce the ratio that the thrust fluctuation accounts for the average thrust from $8 \%$ to $1 \%$. These studies are worthy of celebration and reference.

But, for the low frequency vibration plastic forming equipment driven by slotted - TPMLM, we fell into deep thinking. Why not take advantage of the characteristic of the slotted -TPMLM that can produce a large enough thrust fluctuation?

Many predecessors can reduce the thrust fluctuation by adjusting the physical structure. Similarly, a desired thrust fluctuation used as vibration force can also be produced through the design and adjustment of the physical structure.

Accordingly, an idea that the thrust fluctuation of the slotted - TPMLM is utilized in the low frequency vibration plastic forming equipment is put forward. As shown in Fig.4, in this novel equipment, its core component is the slotted - TPMLM. The motor is used as both the power source and the vibration source. Consequently, the slotted - TPMLM can reciprocate well and must be able to provide a vibration force (thrust fluctuation, $15 \%-45 \%$ of the average thrust, and the frequency of the vibration force is less than $100 \mathrm{~Hz}$ ).

This is the motivation and key point of this paper to carry out the research about thrust fluctuation of the slotted - TPMLM and design the motor that produces the desired thrust fluctuation for the low frequency vibration plastic forming equipment to realize the equipment as shown in Fig.4.
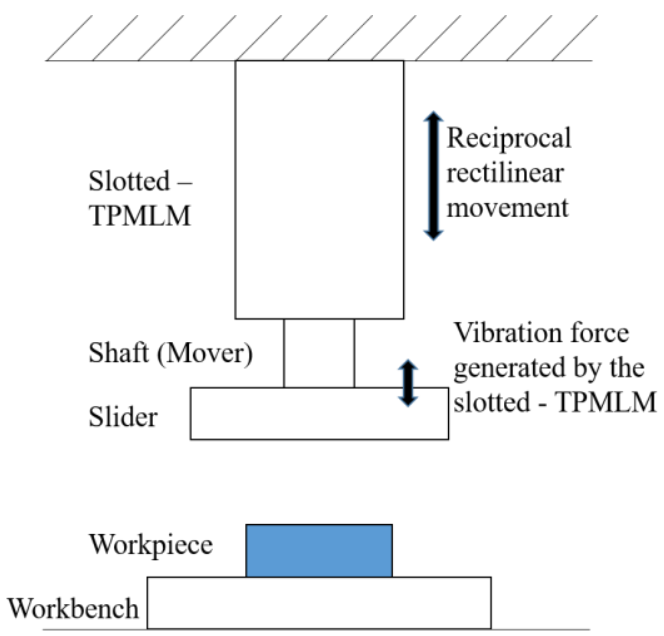

Fig.4 The slotted - TPMLM as both the power source and vibration source in the low frequency vibration forming equipment.

In brief, the thrust fluctuation of the slotted -TPMLM is studied in detail from the structure design and a new slotted TPMLM is designed, manufactured and tested accordingly. Through Fourier analysis, the effect of the length of the stator core on the end force is discussed; the influence of the number of poles and slots on the cogging force is studied. In addition, the electromagnetic thrust force is briefly described. The experimental tests on the thrust fluctuation of the new slotted - TPMLM are carried out to verify and realize the average thrust (forming force) with a certain amplitude and vibration frequency (vibration force), which can meet the desired vibration force for the low frequency vibration plastic forming. The research of this paper promotes the development of linear motor and low frequency vibration plastic forming equipment, and popularized the low frequency vibration plastic forming technology. 


\section{THEORETICAL ANALYSIS OF THRUST FLUCTUATION}

The thrust fluctuation of slotted-TPMLM is caused by magnetostatic resistance, electromagnetic thrust force, load disturbance, system parameter perturbation and so on. The magnetostatic resistance and electromagnetic thrust force are the main factors affecting the thrust fluctuation. The magnetostatic resistance consists of the end force and the cogging force. The magnetostatic resistance is related to the structure and is independent to the excitation current. However, the electromagnetic thrust force is more affected by the excitation current.

In this section, form the structure design, the effect of the length of iron core to the end force and the influence of the number of poles and slots to the cogging force are discussed in detail. Besides, the electromagnetic thrust force is briefly described.

\section{A. End force}

Due to the special structure of the slotted-TPMLM, as shown in Fig.2, the permanent magnet is embedded on the mover and the winding is wound in the stator slots. The finite length of the stator iron core and the finite length of the mover make the mover break at both ends of the stator in the reciprocating motion, resulting in changes in the magnetic conductivity at both ends. Eventually, there will be an end force in the motor's thrust.

The end force is due to the interaction of permanent magnets and the finite length of the iron core. Thus, the tangential thrust components F+ and F- are formed between the end of the stator and the mover, as shown in Fig.5, and the resultant force of these two components is called end force Fend. The end force changes periodically with the pole pitch $\tau$, it can be Fourier analyzed ${ }^{[18,}$ 19, 20].

In this paper, the effect of length of the iron core to the end force is discussed.

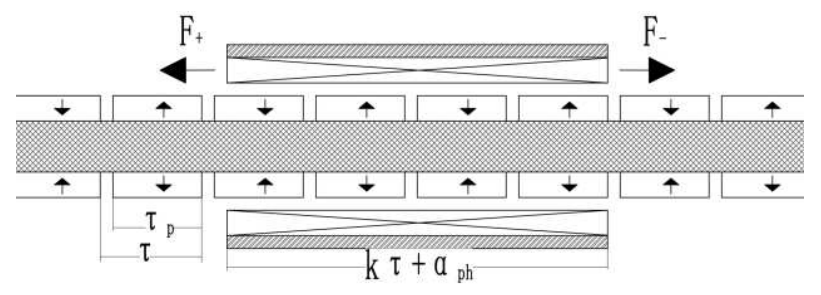

Fig.5 Diagram of TPMLM without slot.

Since the end force is the superposition of the force generated by the two ends of the linear motor, the two ends of the force is first analyzed. The model of the slotted - TPMLM is simplified, as shown in Fig.6. The following assumptions can be made: 1. the stator is of infinite length; 2 . the mover is infinitely long on one side.

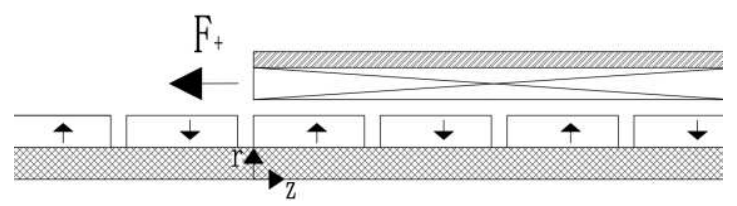

(a) The end force analysis model on the left side

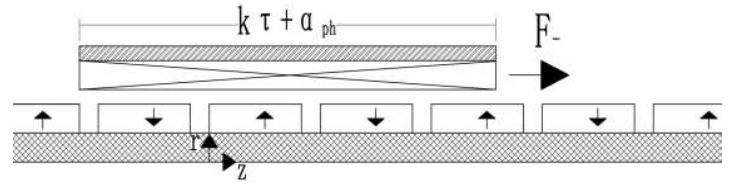

(b) The end force analysis model on the right side

Fig.6 The end force analysis model

Because the end force is periodic at the pole pitch $\tau$, the end force on the left, as shown in Fig. 6 (a), is expanded in Fourier form.

$$
F_{+}(z)=F_{0}+\sum_{n=1}^{\infty} F_{s n} \sin \frac{2 n \pi}{\tau} z+\sum_{n=1}^{\infty} F_{c n} \cos \frac{2 n \pi}{\tau} z
$$

Where, $\mathrm{F}_{0}$ represents the basic end force, $\mathrm{n}$ represents order, $\mathrm{z}$ is the relative position of the mover to a reference position, $\mathrm{F}_{\mathrm{sn}}$ represents the sine function coefficient of order $n$, and $F_{c n}$ represents the cosine function coefficient of order $n$.

As shown in Fig. 6 (b), the end force at the right hand side of the relative position $\left(\mathrm{k} \tau+\alpha_{\mathrm{ph}}\right)$ (the length of the stator iron core, $\mathrm{k}$ is a positive integer, $\alpha_{\mathrm{ph}}$ represents the adjustment of the length of the stator iron core) can be given by the mirror image.

$$
F_{-}(z)=-F_{0}+\sum_{n=1}^{\infty} F_{s n} \sin \frac{2 n \pi}{\tau}\left(z+\alpha_{p h}\right)-\sum_{n=1}^{\infty} F_{c n} \cos \frac{2 n \pi}{\tau}\left(z+\alpha_{p h}\right)
$$

Consequently, the resultant force of the end effect caused by the finite stator length, the finite mover length, and the slot-less 
structure in Fig. 5 can be obtained by superposition principle, namely, the end force is

$$
\mathrm{F}_{\text {end }}(\mathrm{z})=F_{+}(z)+F_{-}(z)=\sum_{n=1}^{\infty} F_{n} \sin \frac{2 n \pi}{\tau}\left(z+\frac{\alpha_{p h}}{2}\right)
$$

Here, $F_{n}$ can be expressed as follows:

$$
F_{n}=2\left[F_{c n} \cos \frac{n \pi}{\tau} \alpha_{p h}+F_{s n} \sin \frac{n \pi}{\tau} \alpha_{p h}\right]
$$

It can be seen from Equations 3 and 4 that when $\left(z+\alpha_{\mathrm{ph}} / 2\right)=0$, the end force is 0 at $\mathrm{z}=-\alpha_{\mathrm{ph}} / 2$. When $\mathrm{n}=1,3,5,7, \ldots$, i.e, the end force is zero. That is the end force generated by the odd-order harmonic can be completely eradicated. On the contrary, the end force generated by the even order harmonics are double.

At the same time, it can also be seen from Fig.5, and Equations 3 and 4 that the end force is related to the length of the iron core $\left(\mathrm{k} \tau+\alpha_{\mathrm{ph}}\right.$, especially $\left.\alpha_{\mathrm{ph}}\right)$ and the relative position of the mover (z). In the case of determining the pole pitch $\tau$, selecting the different length of the stator iron core $\left(\mathrm{k} \tau+\alpha_{\mathrm{ph}}\right)$ can obtain the different end force. Therefore, when the pole pitch $\tau$ is selected, the magnitude and wave of the end force can be adjusted by appropriately selecting $\alpha_{\mathrm{ph}}$. For instance, as shown in Fig.7, it can be seen that different lengths $\alpha_{\mathrm{ph}}$ affect the magnitude and waveform of the end force, which can be used to obtain the desired resultant end force. Accordingly, the desired end force can be obtained by selecting the appropriate length of the stator iron core $\left(\mathrm{k} \tau+\alpha_{\mathrm{ph}}\right)$, pole pitch $\tau$, and especially $\alpha_{\mathrm{ph}}$.

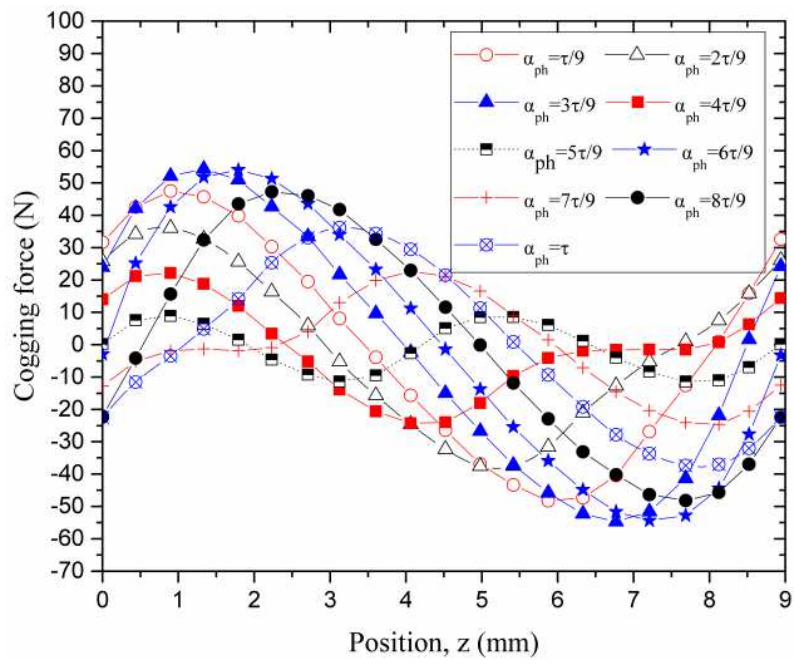

Fig. 7. The effect of $\alpha_{\mathrm{ph}}$ on the magnitude and waveform of the end force.

\section{B. Cogging force}

The cause of cogging force is similar to the reluctance torque of a rotating electric machine. The cogging force caused by the cogging effect is only related to the magnetic field distribution and the cogging structure itself. So, the cogging force is generated by the interaction the PMs and the slots. The cogging force changes periodically with the slot pitch $\tau_{\mathrm{s}}$, it also can be Fourier analyzed ${ }^{[19,21]}$.

For the cogging force of the slotted - TPMLM, the change of air gap permeability caused by stator slot structure is the fundamental reason. So, the cogging force can be designed by adjusting the structural parameters of the slot, adding auxiliary slots, etc ${ }^{[27]}$. But, these methods increase the difficulty of design and manufacture, and may reduce the thrust of the slotted - TPMLM. In addition, the cogging force can be designed by choosing different number of poles and slots, which can obtain desired results. In this paper, the influence of the number of poles and slots to cogging force is discussed.

The cogging force analysis mode is shown in Fig.8. The pole pitch is $\tau$, with evenly distributed slots. The tooth pitch and slot pitch are $\tau_{\mathrm{s}}$. The tooth width is $\mathrm{w}_{\mathrm{t}}$. The slot width is $\mathrm{w}_{\mathrm{s}}$. The tooth pitch $\tau_{\mathrm{s}}$ is the sum of tooth width $\mathrm{w}_{\mathrm{t}}$ and slot width $\mathrm{w}_{\mathrm{s}}$.

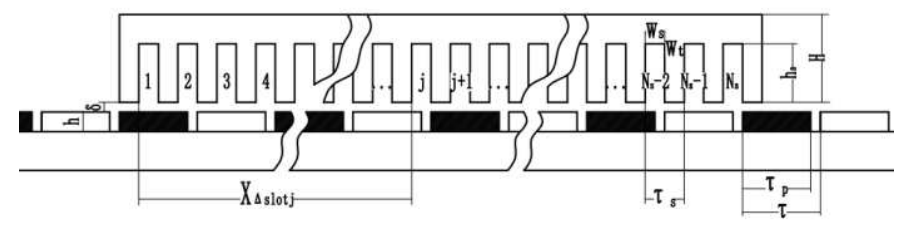

Fig.8 Analysis mode of the cogging force

$$
\tau_{s}=w_{t}+w_{s}
$$

According to the fractional slots theory. 


$$
q_{p}=\frac{\tau}{\tau_{s}}
$$

Here, $\mathrm{q}_{\mathrm{p}}$ represents the number of slots within a pole pitch $\tau$.

When $\mathrm{q}_{\mathrm{p}}$ is an integer, it is an integer slot structure. At this time, the total number of permanent magnets is $\mathrm{N}_{\mathrm{pm}}$, and the cogging force of the integer slotted- TPMLM is $\mathrm{N}_{\mathrm{pm}}$ times of the cogging force generated by a single permanent magnet, which limits the adjustment design of cogging force. When $\mathrm{q}_{\mathrm{p}}$ is a fraction, the cogging force can be designed and adjusted according to requirements. The fractional slot structure can improve and adjust the magnitude of the cogging force well. Therefore, the fractional slot structure is adopted.

In the analysis, it is assumed that the number of slots with uniform distribution is $\mathrm{N}_{\mathrm{s}}$, and its distribution length exactly corresponds to the length of $\mathrm{N}_{\mathrm{p}}$ pole pitch. Both $\mathrm{N}_{\mathrm{s}}$ and $\mathrm{N}_{\mathrm{p}}$ are integers, then the following relation exists:

$$
\begin{aligned}
N_{s} \tau_{s} & =N_{p} \tau \\
q_{p} & =\frac{N_{s}}{N_{p}}
\end{aligned}
$$

The horizontal $\mathrm{N}_{\mathrm{P}}$ permanent magnets are curled into a circular arrangement. At the same time, it is assumed that the $\mathrm{N}_{\mathrm{S}}$ slots horizontally arranged in the linear motor are also curled into a circle and arranged on the periphery of the permanent magnet. The slots will be evenly arranged along the circumference $\left(N_{p} \tau\right)$ of the circle with $N_{p} \tau / N_{s}$ position spacing and evenly distributed along the circumference with $2 \pi / N_{s}$ angular spacing. So, as shown in Fig.9, the position difference $x_{\Delta s l o t}$ and phase Angle difference $\theta_{\Delta s l o t}$ of the Jth slot relative to the first slot are respectively.

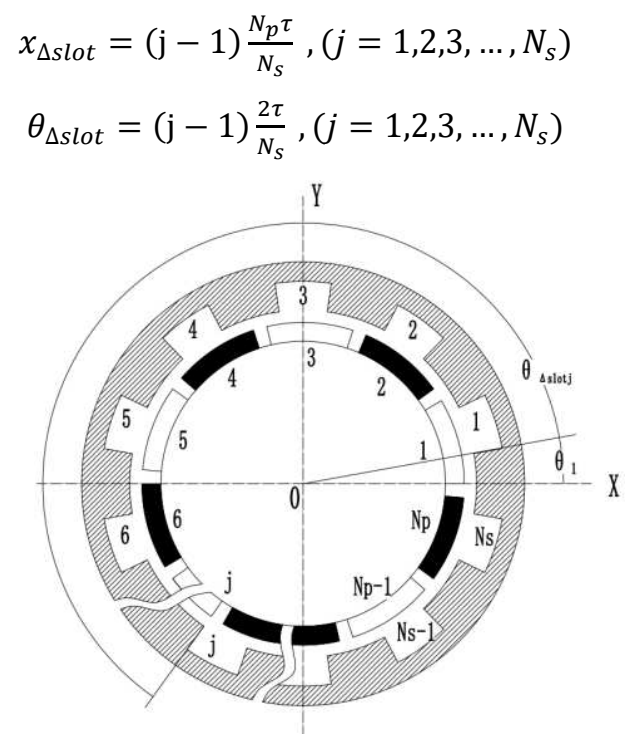

Fig.9 The phase diagram of slotted - TPMLM.

First, we analyze the basic cogging force generated by only one slot. The slot pitch $\tau_{\mathrm{s}}$ is related to the pole pitch $\tau$. It can know that the period of the basic cogging force can be expressed by the pole pitch $\tau$. So, the Fourier series form of the basic cogging force generated by the single slot model is as follows:

$$
F_{b c o g}(x)=\sum_{n=1}^{\infty} F_{n} \sin \left(\frac{2 n \pi}{\tau} x+\theta_{n}\right)
$$

Where, $\mathrm{x}$ is the relative position of the slot relative to a reference position, and $\mathrm{n}$ is the harmonic order and integer, $F_{\mathrm{n}}$ and $\theta_{\mathrm{n}}$ are the amplitude and phase angles of the nth order harmonics.

If the pole pitch $\tau$ corresponds to the $2 \pi$ electric Angle, then the above equation (9) (10) can be simplified as follows:

$$
\begin{gathered}
x_{\Delta s l o t j}=(\mathrm{j}-1) \frac{G C D\left(N_{s}, N_{p}\right)}{N_{s}} \tau,\left(j=1,2,3, \ldots, N_{s}\right) \\
\theta_{\Delta s l o t j}=2(j-1) \frac{G C D\left(N_{s}, N_{p}\right)}{N_{s}} \pi,\left(j=1,2,3, \ldots, N_{s}\right)
\end{gathered}
$$

Where, $G C D\left(N_{s}, N_{p}\right)$ represents the greatest common divisor of $N_{s}$ and $N_{p}$.

Secondly, the superposition principle is used to study the cogging force under multiple slots. The cogging force is a function of the interval $\tau_{\mathrm{s}}$. If the interaction between slots is ignored, the cogging force can be regarded as the superposition of the basic cogging force of each slots. Each basic cogging force has a similar expression to Equation 11, but the phase is different. The cogging force of the Jth slot of the iron core can be expressed as: 


$$
F_{\text {slot }}^{j}(x)=\sum_{n=1}^{\infty} F_{n} \sin \left(\frac{2 n \pi}{\tau}\left(x+x_{\Delta s l o t j}\right)+\theta_{n}\right), j=1,2,3, \ldots, N_{s}
$$

Considering the phase relation between the slots, the superposition of the basic cogging force can get the expression of the total cogging force.

$$
\begin{gathered}
F_{\text {slot }}(x)=\sum_{j=1}^{N_{s}} F_{\text {slot }}^{j}(x)=\sum_{j=1}^{N_{S}} \sum_{n=1}^{\infty} F_{n} \sin \left(\frac{2 n \pi}{\tau}\left(x+(\mathrm{j}-1) \frac{G C D\left(N_{s}, N_{p}\right)}{N_{s}} \tau\right)+\theta_{n}\right)=\sum_{n=1}^{\infty} F_{n}\left[\operatorname { s i n } \left(\frac{2 n \pi}{\tau} \mathrm{x}+\right.\right. \\
\left.\left.\theta_{n}\right) \sum_{j=1}^{N_{S}} \cos \left(n \theta_{\Delta s l o t j}\right)-\cos \left(\frac{2 n \pi}{\tau} \mathrm{x}+\theta_{n}\right) \sum_{j=1}^{N_{s}} \sin \left(n \theta_{\Delta s l o t j}\right)\right]
\end{gathered}
$$

It is easy to prove the following formulas.

$$
\begin{gathered}
\sum_{j=1}^{N_{S}} \sin \left(n \theta_{\Delta s l o t j}\right)=\sum_{j=1}^{N_{S}} \sin \left(2(\mathrm{j}-1) n \frac{G C D\left(N_{s}, N_{p}\right)}{N_{S}} \pi\right)=0 \\
\sum_{j=1}^{N_{S}} \cos \left(n \theta_{\Delta s l o t j}\right)=\sum_{j=1}^{N_{S}} \cos \left(2(\mathrm{j}-1) n \frac{G C D\left(N_{S}, N_{p}\right)}{N_{S}} \pi\right)=\left\{\begin{array}{c}
0, n \neq k N_{s} / G C D\left(N_{s}, N_{p}\right) \\
N_{s}, n=k N_{s} / G C D\left(N_{s}, N_{p}\right)
\end{array}\right.
\end{gathered}
$$

Where, $\mathrm{k}$ is any integer, $\operatorname{GCD}\left(N_{s}, N_{p}\right)$ represents the greatest common divisor of $N_{s}$ and $N_{p}$.

The meaning of the above two expressions (equation 16 and equation 17) is that, when $\mathrm{n}$ is any integer, the value of Equation 16 is identical to 0 ; If $\mathrm{n}$ is any integer multiple of $N_{s} / G C D\left(N_{s}, N_{p}\right)$, the value of Equation 17 is equal to $\mathrm{N}_{\mathrm{S}}$, otherwise the value of Equation 17 is equal to 0 .

Assumption, the multiples of $\mathrm{k}$ are replaced by $\mathrm{n} ; n_{c f}=N_{s} / G C D\left(N_{s}, N_{p}\right)$ is defined; and $\mathrm{n}=\mathrm{n} n_{c f}$ is defined, then the equation 11 can be simplified as:

$$
F_{\text {slot }}(x)=\sum_{n=1}^{\infty} N_{s} F_{n n_{c f}} \sin \left(\frac{2 n n_{c f} \pi}{\tau} x+\theta_{n n_{c f}}\right)
$$

Here, it can be seen from Equation 18 that the total cogging force of the iron core only contains harmonic of order $n_{c f}$ and its frequency doubling components, and other harmonic orders cancel each other out. The amplitude of the residual harmonics is $N_{S}$ times of the amplitude of the corresponding order harmonics of the corresponding basic cogging force.

It is worth mentioning that if $N_{p} \tau$ is defined as $2 \pi$ electric degree Angle, then equation 18 can be expressed as an expression containing only $N_{p} n_{c f}$ harmonic frequency components. Where, $N_{p} n_{c f}$ is the least common multiple of the number of slots $N_{s}$ and the number of poles $N_{p}$.

Equation 18 also shows that the larger $n_{c f}\left(n_{c f}=N_{s} / \operatorname{GCD}\left(N_{s}, N_{p}\right)\right)$ is, the smaller the cogging force of the motor is. Once the number of slots $N_{s}$ or poles $N_{p}$ is selected, the minimum cogging force can be obtained by designing such that there is no common divisor between $N_{s}$ and $N_{p}$. In addition, the greater the maximum common divisor between the number of slots and the number of poles, the greater the cogging force generated by the cogging effect of the motor.

Therefore, we can design a reasonable combination relationship between the number of slots $N_{s}$ and the number of poles $N_{p}$ here to obtain the desired effect of the cogging force, as shown in Table I.

From the table I, it can be seen that when the pole number is 20 and the slot number is 20 , the cogging force is maximum; when the pole number is 20 and the slot number is 30, the cogging force is minimum. Furthermore, the comparison of the cogging force is obtained. 20 poles and 20 slots $>20$ poles and 22 slots $>20$ poles and 26 slots> 20 poles and 24 slots> 20 poles and 28 slots> 20 poles and 30 slots. In this way, the appropriate of the cogging force can be choose according to the influence of number of poles and slots.

TABLE I

N $_{\mathrm{CF}}$ VALUE UNDER DIFFERENT COMBINATION OF SLOT NUMBER AND POLE NUM
\begin{tabular}{|c|c|c|c|c|c|c|c|c|}
\hline$N_{\mathrm{s}}$ & 16 & 18 & 20 & 22 & 24 & 26 & 28 & 30 \\
\hline 16 & 1 & 2 & 4 & 2 & 8 & 2 & 4 & 2 \\
\hline 18 & - & 1 & 2 & 2 & 3 & 2 & 2 & 6 \\
\hline 20 & - & - & 1 & 2 & 4 & 2 & 4 & 10 \\
\hline 22 & - & - & - & 1 & 2 & 2 & 2 & 2 \\
\hline 24 & - & - & - & - & 1 & 2 & 4 & 2 \\
\hline 26 & - & - & - & - & - & 1 & 2 & 2 \\
\hline 28 & - & - & - & - & - & - & 1 & 2 \\
\hline 30 & - & - & - & - & - & - & - & 1 \\
\hline
\end{tabular}

Where, the numbers in the table represent $\left(n_{c f}=N_{s} / G C D\left(N_{s}, N_{p}\right)\right.$.

\section{Electromagnetic thrust force}

The coils of the motor are fed with three-phase symmetrical sinusoidal current (excitation current), and the mover moves 
forward under the action of the traveling wave magnetic field. The electromagnetic thrust force is an important parameter to ensure that stable operation of the motor. Electromagnetic power of the motor is:

$$
P_{e}=3 E_{0} I_{m} \cos \psi
$$

Where, $\psi$ is power factor Angle.

The thrust force of motor is:

$$
F_{e}=\frac{P_{e}}{v_{1}}=\frac{3 E_{0} I_{m} \cos \psi}{v_{1}}=\frac{3 \sqrt{2} \tau N_{i} N_{s} k_{x i} I_{m}}{\pi}\left(B_{a g}+\frac{B_{a g i}}{N_{s}}\right) \cos \psi
$$

The max thrust force is:

$$
F_{\text {max }}=\frac{3 \sqrt{2} \tau N_{i} N_{S} k_{x i} I_{m}}{\pi}\left(B_{a g}+\frac{B_{a g i}}{N_{S}}\right) \cos \psi=\frac{3 \sqrt{2} \tau N_{i} N_{S} k_{x i} I_{m}}{\pi}\left(\frac{\lambda_{0} F_{0}(x)}{2}+\frac{\lambda_{i} F(x)}{N_{S}}\right)
$$

It can be seen that the electromagnetic thrust is affected by the air-gap permeability, air-gap magnetic field strength, poles and so on. The magnitude of the counter potential affects the output of the motor.

\section{DESIGN AND EXPERIMENT}

In this section, the characteristic of existing low frequency vibration plastic forming test of material is summarized, and put forward specific technical indicators for the slotted - TPMLM. Consequently, according to the research of thrust fluctuation of the slotted - TPMLM in the section II, a novel slotted - TPMLM is designed and manufactured, and its test is described.

\section{A. Technique requirement}

According to the previous experiments $(\mathrm{Q} 235,45)$ on metal low frequency vibration plastic forming technology ${ }^{[4,5]}$, the vibration force is $0-3 \mathrm{kN}$ (vibration force accounts for $15 \%-45 \%$ of the forming force) with the frequency is less than $100 \mathrm{~Hz}$, the low frequency vibration plastic processing in this range can improve the metal forming process and improve the quality of products.

Therefore, as shown in Fig.4, the slotted - TPMLM is used as both the power source and the vibration source. Here, when the slotted - TPMLM is designed, it must be able to provide a certain vibration force (vibration force accounts for $15 \%-45 \%$ of the average thrust, where average thrust can be adjusted according to the specific metal forming force) with low frequency under the premise of ensuring normal operation.

\section{B. The design of the slotted - TPMLM}

In the case of meeting the above requirement, in order to facilitate the test and reduce the difficulty of processing and manufacturing, a small slotted - TPMLM is designed and developed to test the thrust fluctuation and explore the feasibility of the special equipment.

Therefore, in the design of slotted - TPMLM, the maximum thrust was designed to be $3.5 \mathrm{kN}$, so that the structure of the motor was reduced. The thrust fluctuation (vibration force) accounts for 15\%-25\% of the average thrust, and the frequency of the thrust fluctuation was less than $50 \mathrm{~Hz}$.

According to the aforementioned research on end force, cogging force, and electromagnetic thrust force, the designed TPMLM is depicted in the Fig.10. The motor adopts the fractional slot concentrated winding structure with 20 poles and 24 slots. The electromagnetic parameters of the linear motor are shown in Table II. The designed TPMLM is manufactured in the Fig.11.

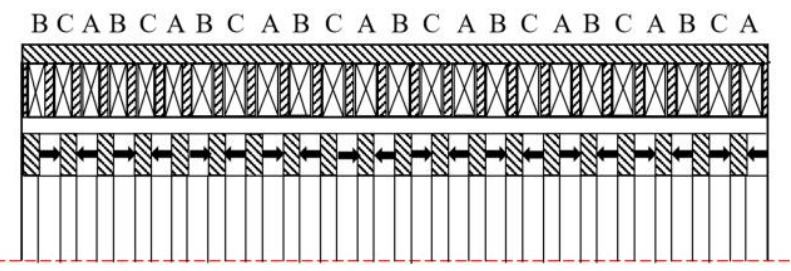

Fig. 10 The structure diagram of TPMLM with 20 poles and 24 slots

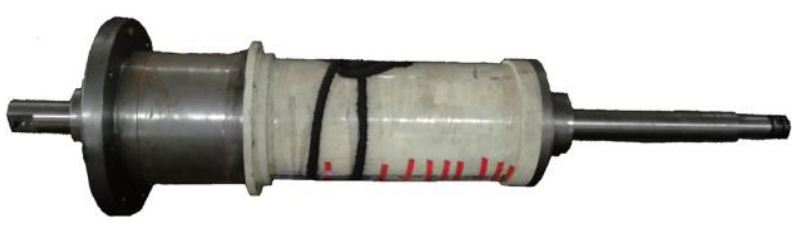

Fig.11. The designed slotted-tubular permanent magnet linear motor. 
TABLE II

ELECTROMAGNETIC PARAMETER OF TPMLM

\begin{tabular}{|c|l|c|}
\hline Number & Parameter & Value \\
\hline 1 & Width of gap & $1.5 \mathrm{~mm}$ \\
\hline 2 & Pole pitch $(\tau)$ & $19.96 \mathrm{~mm}$ \\
\hline 3 & Effective length of stator iron core $\left(\mathrm{k} \tau+\alpha_{\mathrm{ph}}\right)$ & $398.4 \mathrm{~mm}$ \\
\hline 4 & Number of poles $\left(\mathrm{N}_{\mathrm{p}}\right)$ & 20 \\
\hline 5 & Number of slots $\left(\mathrm{N}_{\mathrm{s}}\right)$ & 24 \\
\hline 6 & Slot pitch $\left(\tau_{\mathrm{s}}\right)$ & $16.6 \mathrm{~mm}$ \\
\hline 7 & Stator slot width $\left(\mathrm{w}_{\mathrm{s}}\right)$ & $8.6 \mathrm{~mm}$ \\
\hline 8 & Stator tooth width $\left(\mathrm{w}_{\mathrm{t}}\right)$ & $8.0 \mathrm{~mm}$ \\
\hline 9 & Number of turns of winding & 84 \\
\hline
\end{tabular}

\section{Trailing experiment}

In the trailing test, as shown in the Fig.12, the aim is to obtain the friction and the magnetostatic resistance (end force and cogging force). The test platform is composed of the slotted - TPMLM, a rack and pinion machine, a trailing motor and an aluminum frame. The mover of slotted - TPMLM is connected to the gear rack. The function of the rack and pinion machine is to convert the rotary motion of the trailing motor into a linear motion so that the mover moves. A pull-type displacement sensor is installed between the mover and the aluminum frame for measuring the motion state. A S-type tension sensor is connected between the rack and the mover to obtain the force.

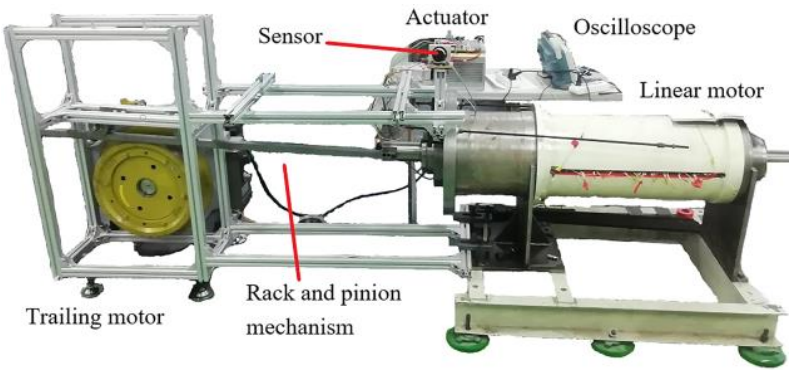

Fig. 12 The trailing test platform

The trailing motor is a permanent magnet synchronous traction machine (Xizi Elevator Co., Ltd.), as shown in Fig.13, which has the characteristics of low speed and high torque, and has excellent speed regulation performance. Table III shows the main technical parameters of the trailing motor. The output force of the trailing motor is about $3300 \mathrm{~N}$ under the rated state.

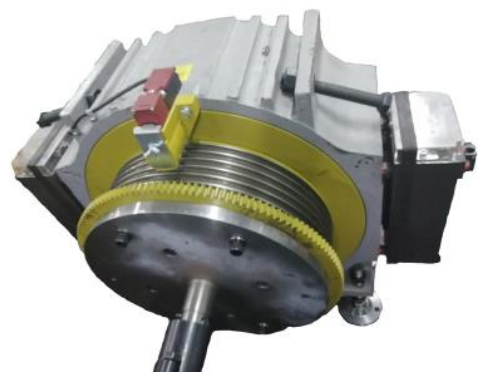

Fig.13 The trailing motor in the trailing experiment

TABLE III

MAIN TECHNICAL PARAMETERS OF TRAILING MOTOR

\begin{tabular}{|c|c|c|c|}
\hline Rated power & Rated speed & Rated torque & Gear pitch \\
\hline $11.7 \mathrm{~kW}$ & $167 \mathrm{r} / \mathrm{min}$ & $667 \mathrm{~N} \cdot \mathrm{m}$ & $400 \mathrm{~mm}$ \\
\hline
\end{tabular}




\section{Load experiment}

The electromagnetic thrust force of TPMLM cannot be directly measured. In order to obtain the electromagnetic thrust force, only an indirect method can be used for verification.

The load experiment studies the thrust fluctuation characteristics of slotted - TPMLM, especially the electromagnetic thrust force, when the three-phase sinusoidal excitation current is applied. As shown in the Fig.14, the load test includes five parts: air cylinder, slotted - TPMLM, force sensor, displacement sensor and experimental base. The air cylinder can adjust the pressure and maintain a constant resistance. The mover will push the air cylinder to move together. At this time, the force sensor can measure the thrust fluctuation of the mover, and the displacement sensor can measure the movement. Table IV shows the main technical parameters of the air cylinder.

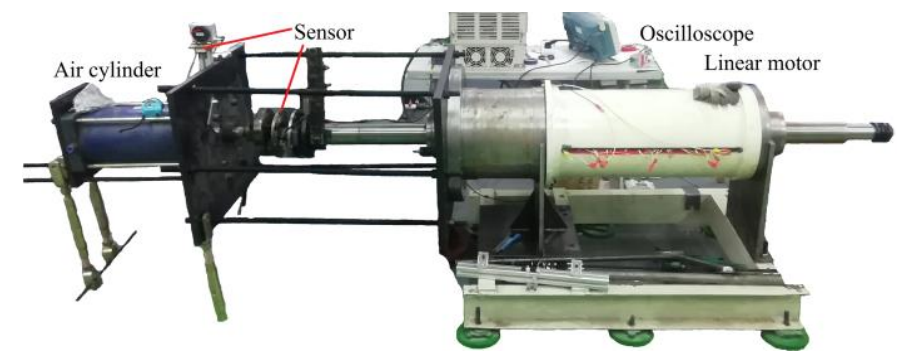

Fig. 14. The load experiment platform

TABLE IV

MAIN TECHNICAL PARAMETERS OF CYLINDER

\begin{tabular}{|c|c|c|c|}
\hline \multicolumn{4}{|c}{ MAIN TECHNICAL PARAMETERS OF CYLINDER } \\
\hline $200 \mathrm{~mm}$ & $350 \mathrm{~mm}$ & $30-800 \mathrm{~mm} / \mathrm{s}$ & $0.03-1.0 \mathrm{MPa}$ \\
\hline
\end{tabular}

The load capacity of the air cylinder can be calculated using the pressure formula.

$$
F_{F}=\eta_{F} P_{F} S
$$

Where, $\eta_{\mathrm{F}}$ is air output efficiency of the air cylinder; $\mathrm{P}_{\mathrm{F}}$ is pressure range of the air cylinder; $\mathrm{S}$ is piston area of the air cylinder.

\section{RESULTS AND DISCUSS}

In this section, for the slotted - TPMLM designed and manufactured in chapter III, the results obtained from the tailing experiment and load experiment are analyzed. The reliability of the slotted TPMLM is verified, and the feasibility of the low frequency vibration plastic forming equipment driven by the slotted TPMLM as shown in Fig.4 is discussed.

\section{A. The friction and magnetastic resistance}

Since the friction and the magnetostatic resistance (end force and cogging force) are only related to the mechanical structure and the magnetostatic resistance is a function of the relative position of the mover, the friction and the magnetostatic resistance should are first obtained in the trailing experiment, as shown in Fig.12.

In order to fully achieve the electromagnetic conditions without electromagnetic thrust force, it is necessary to short-circuit the three-phase coils of slotted - TPMLM and form a closed loop. The voltage signal output measured by the S-type pull pressure sensor is converted into a force curve.

Fig.15. (a) is a thrust fluctuation curve throughout the whole process. In the Fig.15 (a), it can be divided into three segments: front segment, middle segment, and back segment. The front and back segments in Fig.15 (a) are the force obtained when the motion is stopped. The middle segment of Fig.15.a shows the force obtained during motion, here, the velocity of the mover is approximately $100 \mathrm{~mm} / \mathrm{s}$. Fig.15 (b) is a local enlarged figure of this force. Fig.16 is the Fourier spectrum analysis about Fig.15 (b).

When the trailing motor is not rotating, this means that the mover is not moving (there is no change in relative position). As shown in the front and back segments in the Fig.15 (a), the fluctuation of force is mainly the result of the combination of the static friction force and magnetostatic resistance (end force and cogging force). The average force is maintained near $0 \mathrm{~N}$. The range of fluctuation is about $60 \mathrm{~N}$. In this satiation, the end force and the cogging force may have a tendency to push the mover to move. The static friction force has the ability to inhibit the tendency of the mover to move. On the whole, this kind of comprehensive influence causes the mover of the slotted - TPMLM to have the tendency of reciprocating motion at this time, but in fact, there is no relative position movement, only showing the thrust fluctuation at this moment.

When the trailing motor rotates, this means that the mover is moving (there is a change in relative position), the motion of the trailing motor and the linear motor is in balance state. As shown in the middle segment in the Fig.15 (a), that is Fig.15 b, the fluctuation of force is mainly the result of the combination of the sliding friction force and magnetostatic resistance (end force and 
cogging force).

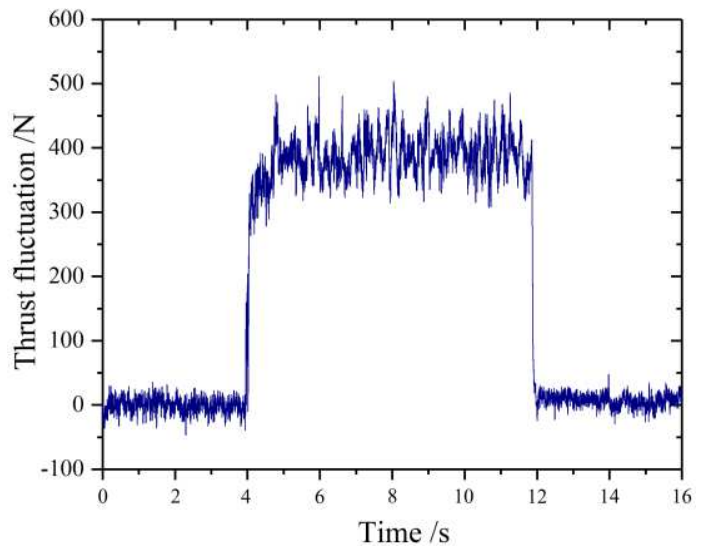

(a) The thrust fluctuation throughout the whole process. (Where, the velocity of the mover is approximately $100 \mathrm{~mm} / \mathrm{s} \mathrm{during} \mathrm{running}$ )

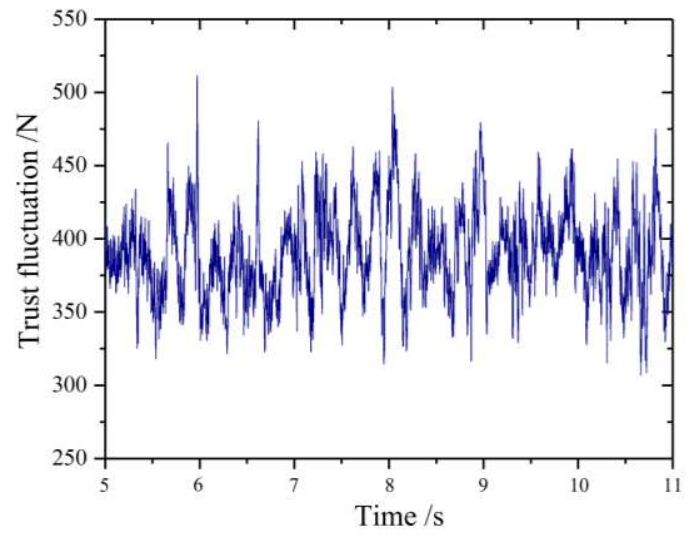

(b) The thrust fluctuation in the middle segment.

Fig. 15. The thrust fluctuation. (a. the thrust fluctuation throughout the whole process; b. enlarged figure of the thrust fluctuation during motion). (Where, the velocity of the mover is approximately $100 \mathrm{~mm} / \mathrm{s}$ )

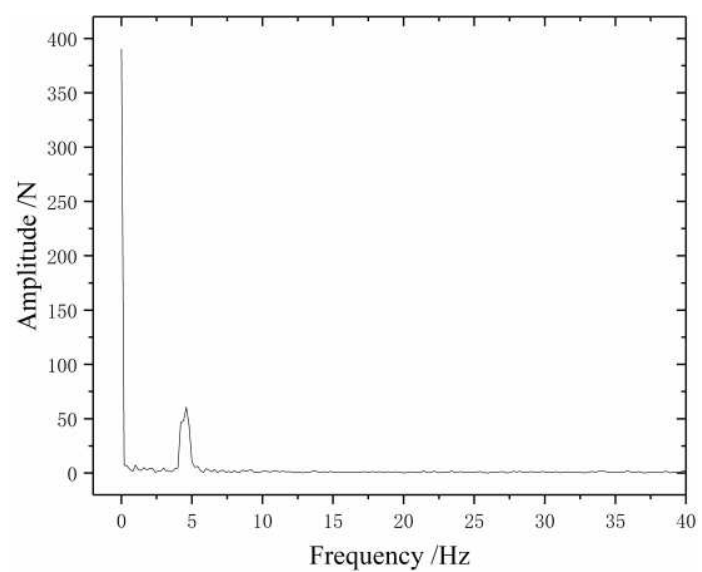

Fig.16 The Fourier spectrum analysis of the thrust fluctuation. (Where, the velocity of the mover is approximately $100 \mathrm{~mm} / \mathrm{s}$ )

The thrust fluctuation is between $330 \mathrm{~N}$ and $450 \mathrm{~N}$, and the range is about $120 \mathrm{~N}$. Since the shape of the linear motor is cylindrical, the normal suction can be well balanced, and the pressure between the mover and the stator can be considered to be a constant value. the surface roughness is basically maintained consistent. According to the sliding friction calculation formula (21), the sliding friction is a constant value. Thereby, the friction mainly affects the average of thrust fluctuation. The friction is $390 \mathrm{~N}$, and the direction is opposite to the direction of motion of the mover.

$$
\mathrm{f}=\mu \cdot F_{N}
$$

where, $\mu$ is kinetic friction factor, $\mathrm{F}_{\mathrm{N}}$ is the pressure between the mover and the stator.

From the force fluctuation in Fig.15 (b), it can be seen that the waveform is approximately sine. In Fig.16, the Fourier spectrum 
analysis of the experimental results shows that there are mainly two frequency spectra, one is the fundamental frequency and the other is about $4.5 \mathrm{~Hz}$.

The tooth pitch $\tau_{\mathrm{s}}$ is the period of the cogging force, and the pole pitch $\tau$ is the period of the end force, and there is a relationship between the tooth pitch $\tau_{\mathrm{s}}$ and the pole pitch $\tau$, so both the cogging force and the end force can be expressed with the pole pitch $\tau$ as the period. Therefore, the magnetostatic resistance (cogging force and end force) is a function, and the function is a periodic function, and the period is the pole pitch $\tau$ of the motor. When the mover is conducted at approximately $100 \mathrm{~mm} / \mathrm{s}$, the pole pitch $\tau$ of the designed motor is $19.96 \mathrm{~mm}$, and the period of the magnetostic resistance is calculated theoretically to be about $5.0 \mathrm{~Hz}$ according to the equation 22

However, in the experiment, the period of the magnetostic resistance is about $4.8 \mathrm{~Hz}$, as show in Fig.16. It can be known that there is a certain difference between the experimental result and the theoretically calculation of the magnetic resistance frequency analysis. The experimental result is $4.8 \mathrm{~Hz}$, while the theoretical calculation is $5.0 \mathrm{~Hz}$. The difference may be due to errors in the manufacturing and assembly process.

Most of all, $4.8 \mathrm{~Hz}$ in the experimental result or $5.0 \mathrm{~Hz}$ in the theoretical result all represent the frequency of the resultant force of thrust fluctuations, indicating that the desired thrust fluctuation is low frequency thrust fluctuations.

$$
\mathrm{f}=\frac{v}{\tau}
$$

where, $f$ represents the fluctuation period of magnetostic resistance; $v$ is the velocity of the mover of the slotted - TPMLM; $\tau$ is the pole pitch of the motor.

\section{B. Electromagnetic thrust force}

In the load experiment shown in Fig.14, the slotted - TPMLM is directly driven by the excitation current, and the thrust characteristics of the slotted - TPMLM is discussed. At this time, the thrust fluctuation is affected by magnetostatic resistance (end force and cogging force), electromagnetic thrust force, frictional resistance and other aspects. Here, we mainly investigate the influence of electromagnetic thrust force on the output thrust of slotted - TPMLM.

Fig.17 shows the thrust fluctuation characteristic of slotted - TPMLM under different excitation current. Fig. 17 (a) shows that when the excitation current is $3 \mathrm{~A}$, the average thrust is $1750 \mathrm{~N}$, and the range of thrust fluctuation is $210 \mathrm{~N}$. Fig. 17 (b) shows that when the excitation current is $5.6 \mathrm{~A}$, the average thrust is $4200 \mathrm{~N}$, and the range of thrust fluctuation is $400 \mathrm{~N}$.

At this point, the thrust fluctuation is affected by the superposition of sliding friction force, magnetostatic resistance (end force and cogging force), and electromagnetic thrust force. Because the magnetostatic resistance is only related to the physical structure of the slotted - TPMLM and is the position function of the mover, the range of fluctuation caused by the electromagnetic thrust force can be calculated ( $90 \mathrm{~N}$ at $3 \mathrm{~A}$, and $280 \mathrm{~N}$ at $5.6 \mathrm{~A}$, respectively).

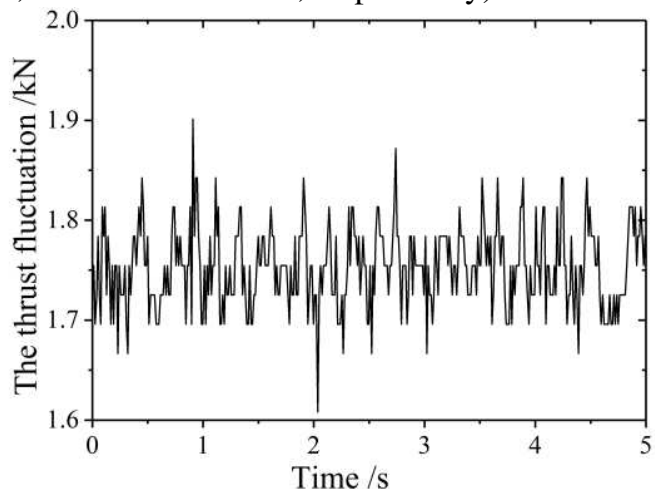

(a) The thrust fluctuation at 3.0 A excitation current

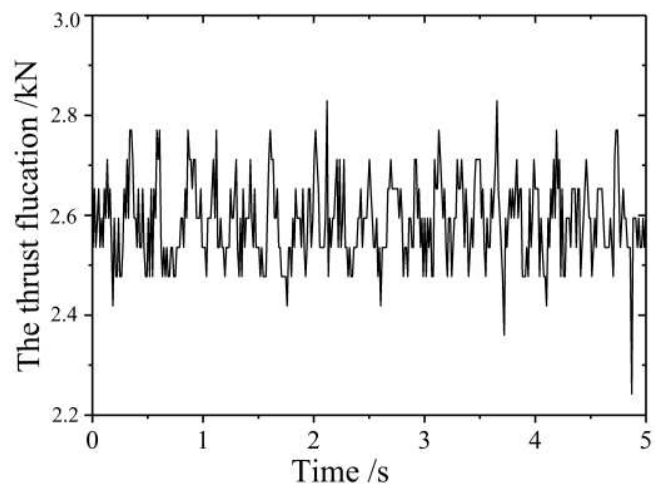

(b) The thrust fluctuation at 5.6 A excitation current

Fig. 17. The thrust fluctuation at different excitation currents. (a. the excitation current is 3 A; b. the excitation current is 5.6 A) 
As shown in Fig. 18, (a) shows a relationship curve between the thrust fluctuation and the excitation current, (b) expresses a relationship curve between the average thrust and the excitation current, and (c) reveals a relationship curve between the ratio of the thrust fluctuation to the average thrust and the excitation current.

It can be seen from Fig.18 (b) that the average thrust increases proportionately with the increase of the excitation current. When the excitation current increases to $5 \mathrm{~A}$, the growth rate of the average thrust gradually decreases.

As can be seen from Fig.18 (a), when the excitation current is small (less than 2A), the thrust fluctuation is small (less than $200 \mathrm{~N}$, about $175 \mathrm{~N}$ ). Here, the thrust fluctuation caused by magnetostatic resistance (end force and cogging force) plays a dominant role. As shown in Fig.18 (c), at this time, the thrust fluctuation accounts for a large proportion (greater than 20\%) of the average thrust.

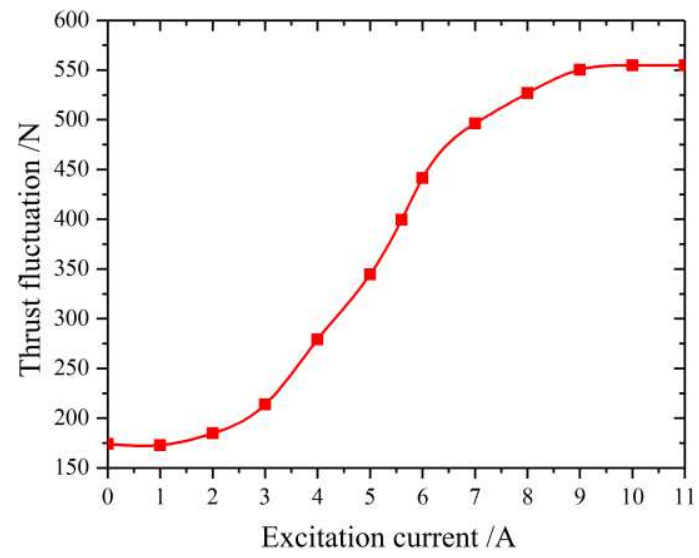

(a) A relationship curve between the thrust fluctuation and the excitation current

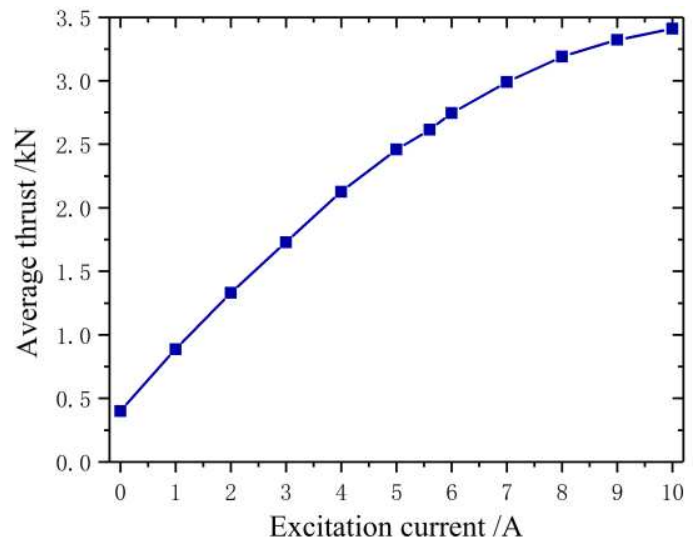

(b) A relationship curve between the average thrust and the excitation current

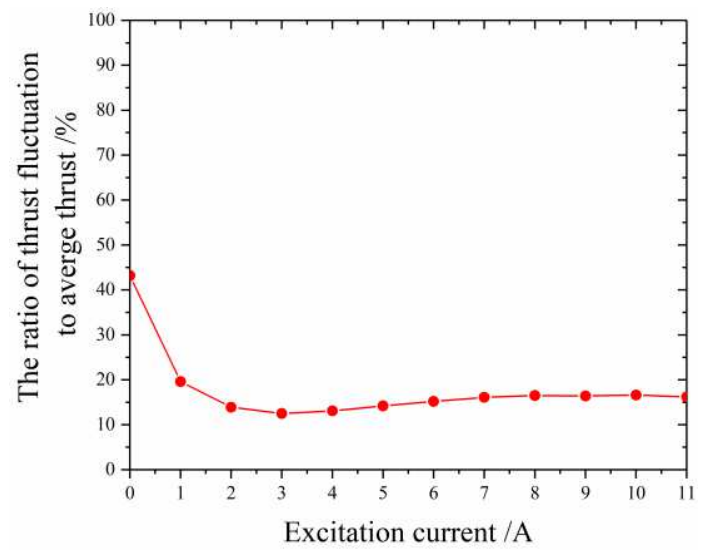

(c) A relationship curve between the ratio of the thrust fluctuation to the average thrust and the excitation current.

Fig. 18. Diagram of mechanical properties under different excitation current.

As shown in Fig.18 (a), when the excitation current increases (greater than 2A and less than 7A), the thrust fluctuation 
increases (increases in a certain linear proportion). Here, the thrust fluctuation due to the magnetostic resistance is still about $120 \mathrm{~N}$. When the excitation current is $5 \mathrm{~A}$, the thrust fluctuation is about $350 \mathrm{~N}$, of which the thrust fluctuation caused by the excitation current is about $230 \mathrm{~N}$; When the excitation current is $7 \mathrm{~A}$, the thrust fluctuation is about $500 \mathrm{~N}$, of which the thrust fluctuation caused by the excitation current is about 380N; As shown in Fig.18 (c), at this time, when the excitation current is between $2 \mathrm{~A}$ and $7 \mathrm{~A}$, the thrust fluctuation accounts for about $16.5 \%$ of the average thrust.

As shown in Fig.18 (a), when the excitation current continuous to increase (greater than 7A), the thrust fluctuation gradually becomes stable (about 550, when the excitation current is greater than 9A). At this time, the thrust fluctuation caused by the magnetostic resistance is still about $120 \mathrm{~N}$, while the thrust fluctuation caused by excitation current is about $430 \mathrm{~N}$. The electromagnetic thrust fluctuation caused by the excitation current is dominant factor. When the excitation current increases to $9 \mathrm{~A}$, the fluctuation reaches a stable state, which is caused by the saturation of the magnetic field within the pole pitch caused by the excitation current.

By analyzing the ratio of the thrust fluctuation to the average thrust under different excitation currents, as shown in Fig.18 (c), it can be seen that when the excitation current exceeds $2 \mathrm{~A}$, as the average thrust increases, the thrust fluctuation always remains about $15 \%$ of the average thrust. In addition, the frequency of the thrust fluctuation is in the low frequency range (less than 100 $\mathrm{Hz}$ ). So, the thrust fluctuation of slotted- TPMLM is in a reasonable range, reaching the designed goal, and meet the application requirements of low frequency vibration plastic forming equipment.

\section{The discussion on the low frequency vibration plastic forming equipment driven by the slotted - TPMLM}

From the perspective of motor optimization design, thrust fluctuations cannot be completely eliminated. However, from the perspective of utilization and application, under the premise of ensuring the normal operation, the thrust fluctuation of the slotted - TPMLM can be reasonably introduced into low frequency vibration plastic forming, as shown in Fig.4, and the slotted - TPMLM is used as both the power source and the vibration source. The equipment is conducive to achieving better plastic forming processes, such as extrusion and cold forging.

Through the analysis of the thrust fluctuation of the slotted - TPMLM, there are two main types of thrust fluctuations. One is the magnetostatic resistance (end force and cogging force) related to physical structure; the other is electromagnetic thrust force related to the excitation current. However, the magnetostatic resistance is only a function of the relative position of the mover without the excitation current; the electromagnetic thrust force is related to the excitation current. In this article, the foucs is one the magnetostatic resistance (end force and cogging force) caused by the structure of the motor. Design a reasonable end force by selecting the length of the stator iron core; and design a reasonable cogging force by selecting the numbers of slots and poles.

From the trailing experiment, when there is no excitation current, it can be seen that the magnetitude of the magnetostatic resistance (end force and cogging force) is about $120 \mathrm{~N}$. and its frequency is in the low frequency range. For example, When the running speed of the motor is about $100 \mathrm{~mm} / \mathrm{s}$, the frequency of magnetostatic resistance is $4.5 \mathrm{~Hz}$; When the running speed of the motor is about $1000 \mathrm{~mm} / \mathrm{s}$, the frequency of magnetostatic resistance can be $45 \mathrm{~Hz}$.

From the load experiment, it is found that the thrust fluctuation can reach up to about $550 \mathrm{~N}$, which is caused by the change of internal magnetic field of the motor caused by the injecting of the excitation current. When the excitation current is greater than $2 \mathrm{~A}$, the proportion of the thrust fluctuation to the average is stable about $16.5 \%$. For example, when the excitation current is $9 \mathrm{~A}$, the average thrust is about $3.25 \mathrm{kN}$, the thrust fluctuation is about $550 \mathrm{~N}$, and the proportion of the thrust fluctuation to the average thrust is about $16.9 \%$. These tests show that the slotted - TPMLM designed can meet the requirements of low frequency vibration plastic forming technology and equipment.

Therefore, the mechanical structure of TPMLM can be manufactured for specific occasions to change the fluctuation of the magnetostatic resistance. But, once the mechanical structure is determined, the magnetostatic resistance is relatively constant. Furthermore, after determining the mechanical structure of TPMLM, the electromagnetic thrust force is the main regulating means by the excitation current (greater than $2 \mathrm{~A}$ ).

\section{CONCLUSION}

1. The magneticostatic resistance (cogging force and end force) is related to the structure. The desired resultant end force can be obtained by selecting the length of the stator iron core $\alpha_{\mathrm{ph}}$. The desired cogging force can be obtained by selecting the number of slots and poles. Therefore, the mechanical structure of TPMLM can be designed for specific occasions to obtained desired thrust fluctuation as basic thrust fluctuation, which is caused by the magneticostatic resistance related to the structure. In addition, because magnetostatic resistance is only a function of the relative position of the mover, which shows that the fluctuation period of the magnetostic resistance is related to the ratio of the velocity of the mover to the pole pitch, indicating that the thrust fluctuation caused by the magnetostic resistance is adjustable and low frequency.

2. In addition to the magnetostatic resistance caused by the motor structure, the thrust fluctuations caused by the electromagnetic thrust force related to the excitation current also important. The experiment shows that the thrust fluctuation caused by the electromagnetic thrust gradually dominates with the increase of the excitation current. When the excitation current exceeds $2 \mathrm{~A}$, the thrust fluctuation of the slotted - TPMLM is always maintained at about $16.5 \%$ of the average thrust. Once the mechanical structure is determined, the magnetostatic resistance is relatively constant. The thrust fluctuation can be adjusted by 
electromagnetic thrust force to obtained more fluctuation.

3. From the perspective of application, on the premise of ensuring slotted -TPMLM normal operation, reasonable mechanical structure can be designed to increase the cogging force and end force. Through the experiments shows that the thrust fluctuation can be applied to low frequency vibration plastic forming equipment, as shown in Fig.4, and the special equipment can be realized. In other words, the thrust fluctuation of $16.5 \%$ of the average thrust of slotted -TPMLM can be designed and realized, and its frequency is in the low frequency range (less than $100 \mathrm{~Hz}$ ). Consequently, the low frequency vibration plastic forming equipment can be realized, which contributes to the field of the plastic forming.

\section{DECLARATIONS}

\section{A. Availability of data and materials}

The datasets used and/or analysed during the current study are available from the corresponding author on reasonable request.

\section{B. Competing interests}

The authors declare that they have no competing interests

\section{Funding}

The present work is finically supported by the National Natural Science Foundation of China (51335009), State key Laboratory for Mechanical Behavior of Materials (1991DA105206), and the Joint Funds of the Natural Science Foundation of Shaanxi Province (Grant No.2019JLP-06).

\section{Authors' contributions}

Jingzhou Gao analyzed, researched and wrote this paper; Jingxiang Li analyzed, researched and polished the paper; Shengdun Zhao supervised the paper; Jingzhou Gao, Wei Du, Fei Jiang, Zhenhao Zheng and Xinchu Wu carried out the design, manufacture and experimental test of the slotted -TPMLM. All authors read and approved the final manuscript

\section{E. Acknowledgements \\ Not applicable.}

\section{REFERENCES}

[1] Wu Xiao, Li Jianjun, Zheng Zhizhen and Chen Xuedong, Research and application progress of metal plastic forming mechanism under vibration field, Journal of Plasticity Engineering, Vol.22, No.4, pp.1-7, Aug. 2015. (in Chinese)

[2] Meng Dean, Zhao Shengdun, Li Yongyi, Li Jingxiang and Fan Shuqin, Key technology of plastic forming with low frequency vibration, Journal of Plasticity Engineering, Vol.21, No.4, pp. 7-12, Aug. 2014. (in Chinese)

[3] Kircher H O K, Kromp W K, Prinz F B, et al. Plastic deformation under simultaneous cyclic and unidirectional loading at low and ultrasonic frequencies [J]. Materials Science and Engineering, Vol.68, No.2, pp:197-206,1985.

[4] Jiang Zhihong, Wang Baoyu, Gong Yaoteng and Huang Xinjian, Tensile deformation behavior of Q235A Steel under low frequency vibration, Materials for mechanical engineering, Vol.41, No.6, pp.14-16, 2017. (in Chinese)

[5] Jiang Zhihong, Wang Baoyu and Xiao Wenchao, Mechanical behaviors of steel 45 during compression in the low frequency vibration, Journal of plastic engineering, Vol.24, No.3, pp.166-179, 2017. (in Chinese)

[6] B. Yang and M. Yang, Optimization of metal foils surface finishing using vibration-assisted micro-forging, Journal of Materials Processing Technology, Vol.214, pp.21-28, 2014.

[7] K. Osakada, K. Mori and T. Altan, Mechanical servo press technology for metal forming, CIRP Annals-Manufacturing Technology, Vol.60, pp.651-672, 2011.

[8] Halicioglu. R, Dulger. LC and Bozdana. AT. Mechanisms, classifications, and applications of servo presses: A review with comparisons, Proceedings of the institution of mechanical. Engineering. part B- Journal of engineering manufacture, Vol.230, pp:1177-1194, 2016.

[9] B.A. Behrens, R. Krimm, D. Reich and S. Teichrib, Linear drives in metal forming machines and peripherals- recent development, Journal of Manufacturing Processes, Vol.22, pp.192-198, 2016.

[10] Zhao Shengdun, Zhang Peng, Fan Shuqin, et al, Discussion on intelligent forging equipment and approaches of its implementation, Forging \& Stamping technology, Vol.43, No.7, pp:32-48, 2018. (in Chinese)

[11] Chen Chao, Fan Shuqin, Zhao Shengdun, et al, Research on structure and key technology of the press driven by linear motor, Machine tool \& Hydraulics, Vol.44, No.11, pp:61-65, 2016. (in Chinese)

[12] Cao Ruiwu, Lu Minghang, Reduction of thrust force ripple of high temperature superconducting linear flux-switching motors using asymmetry mover structure, IEEE Transactions on Applied superconductivity, Aug. 2021.

[13] Xu wei, Ali Mosaad M, Elmorshedy Mahmoud F, Allam Said M, One improved sliding mode DTC for linear induction machines based on linear metro, IEEE Transactions on power electronics, Vol.36, No.4, pp:4560-4571, 2021.

[14] Delli Colli Vincenzo, Cancelliere Piergiacomo, Marignetti Fabrizio, A tubular generator drive for wave energy conversion, IEEE Transactions on Industrial Electronics, Vol,53, No.4, pp:1152-1159,2016.

[15] Zhao Jing, Mou Quansong, Guo Keyu, Li Bin, Liu Xiangdong, Thrust optimization of tubular C-core modular linear permanent magnet synchronous motor, 22nd International conference on electrical machines and systems (ICEMS 2019). 
[16] Ren ningning, Li huaishu, Xue Zhiqiang, Zhouyu, Research on thrust fluctuation of tubular permanent magnet linear synchronous motors with unequal pole-pitch, Journal of Harbin Engineering University, Vol.38, No.2, pp:241-246, 2017.

[17] Zhu ShaoHong, Zheng Ping, Yu Bin, Cheng Luming, Wang Weinan, Performance analysis and modeling of a tubular staggered tooth transverse flux PM linear machine, Energies, Vol.9, No.3, 2016.

[18] P.J. Hor, Z.Q. Zhu, D. Howe and J. Rees-Jones, Minimization of cogging force in a linear permanent magnet motor, IEEE T MAG, Vol.34, No.5, 1998.

[19] Z.Q. Zhu, P.J. Hor, D. Howe and J.Rees-Jones, Calculation of cogging force in a novel slotted linear tubular brushless permanent magnet motor, IEEE T $M A G$, Vol.33, No.5, 1997.

[20] Z.Q. Zhu, Z.P. Xia, D. Howe and P.H. Mellor, Reduction of cogging force in slotless linear permanent magnet motors, IEEE Proc.-Electr. Power Appl, Vol.144, No.4, 1997.

[21] H.X. Wu, L.Y. Li and B.Q. Kou, Cogging force analysis of tubular linear permanent magnet motors, 2008 International Conference on Electrical Machines and Systems.

[22] B.Q. Kou, L.Y. Li and C.M. Zhang, Analysis and optimization of thrust characteristics of tubular linear electromagnetic launcher for space-use, IEEE T $M A G$, Vol.45, No.1, 2009.

[23] L.Y. Li, X.Z Huang and D.H. Pan, Magnetic field of a tubular linear motor with special permanent magnet, IEEE T PLASMA SCI, Vol.39, No.1, 2011.

[24] Q. Tan, X.Z. Huang and L.Y. Li, Research on inductance unbalance and thrust ripple suppression of slot-less tubular permanent magnet synchronous linear motor, IEEE Access, 2018.

[25] Q. Tan, X.Z. Huang and L.Y Li, Analysis of flux linkage and detent force for a modular tubular permanent magnet synchronous linear motor with large slots, IEEE T ENG CONVERSION, Vol.34, No.3, 2019.

[26] X.Z. Huang, Q. Tan and C.M. Zhang, Design principles of a phase-shift modular slotless tubular permanent magnet linear synchronous motor with three sectional primaries and analysis of its detent force, IEEE T IND ELECTRON, Vol.65, No.12, 2018.

[27] P.F Hou, K.F Huang and P.Y Wang, Cogging force reduction for tubular permanent magnet linear motor by slots with different sizes, Journal of Vibro engineering, Vol.20, 2018.

[28] N. Bianchi, S. Bolognani and F. Tonel, Design criteria of a tubular linear IPM motor, IEEE International Electric Machines \& Drives Conference, 2001.

[29] J.B. Wang, David Howe and Geraint W. Jewell, Analysis and design optimization of an improved axially magnetized tubular permanent-magnet machine, IEEE T ENERGY CONVER, Vol,19, No.2, 2004.

[30] M. Ashabani, Y. A-R. I. Mohamed and J. Milimonfared, Optimum design of tubular permanent-magnet motors for thrust characteristics improvement by combined taguchi-neural network approach, IEEE T MAG, Vol.46, No.12, 2010.

[31] K.L. Pan, J.Z. Fu and Z.C Chen, Detent force analysis and reduction of PMLSM, Proceedings of CSEE, Vol.24, No,4, 2004.

[32] J.H Zhao and J.H Zhang, Tubular permanent magnet linear synchronous motor thrust optimization, Advanced materials research, Vol.383-390, pp.5640$5647,2012$.

[33] AW van Zyl and CF Landy, Reduction of cogging forces in a tubular linear synchronous motor by optimizing the secondary design, IEEE Africon, 2002.

[34] Q. Wang, B. Zhao and H. Zhao, Optimal design of tubular transverse flux motors with low cogging forces for direct drive applications, IEEE TAPPL SUPERCON, Vol.26, No.7, 2016. 